\title{
Patients with essential tremor can have manual dexterity and attention deficits with no impairments in other cognitive functions
}

\author{
Pacientes com tremor essencial podem apresentar prejuízo na destreza manual e déficit \\ de atenção sem prejuízo em outras áreas da cognição \\ Leonardo Mariano Inácio Medeiros', Pollyanna Celso Felipe de Castro, André C. Felício 1,2, Bárbara Bernardo \\ Queiros', Sonia Maria Cesar Azevedo Silva', Henrique Ballalai Ferraz', Paulo Henrique Ferreira Bertolucci', \\ Vanderci Borges ${ }^{1}$
}

\begin{abstract}
Essential tremor (ET) was long believed to be a monosymptomatic disorder. However, studies have evidenced structural changes and attention is now being focused on non-motor symptoms. The objective of the study is to describe and compare ET patients with control groups according to their cognitive functions, and secondarily, to compare their sociodemographic characteristics and other clinical features. All participants were assessed using the Fahn-Tolosa-Marin Tremor Rating Scale for the severity of tremor; a neuropsychological assessment battery and a screening questionnaire for mood and anxiety symptoms. There were no significant age and gender differences between all groups. As for neuropsychological assessment results, a significant difference was found only in the Pegboard test. We also found a significant negative correlation between a poorer cognitive test results and disease severity and a significant differences regarding depression or anxiety symptoms in patients with ET. The study results suggest that patients with ET have impaired manual dexterity and attention.
\end{abstract}

Keywords: essential tremor, cognition, anxiety, depression, manual dexterity.

\section{RESUMO}

O tremor essencial (TE) era considerado como um transtorno monossintomático. Contudo estudos tem demonstrado alterações anatômicas despertando o interesse para sintomas não-motores. o objetivo do estudo é descrever e comparar pacientes com grupos controles segundo suas funções cognitivas, e secundariamente, comparar suas características demográficas e outros sintomas clínicos. Todos os participantes foram submetidos à escala de Fahn, Tolosa e Marin para avaliação da intensidade do tremor, a uma bateria neuropsicológica e a um questionário para detecção de transtorno de humor e ansiedade. Não houve diferença significativa na idade e gênero entre todos os grupos. Quanto ao resultado da avaliação neuropsicológica, foi encontrado uma diferença significativa apenas no Test Pegboard. Nós também encontramos uma correlação negativa no desempenho dos testes cognitivos e intensidade do tremor, presença de sintomas depressivos e ansiosos. Os resultados deste trabalho sugerem que pacientes com TE apresentem alteração na destreza manual e na atenção.

Palavras-chave: tremor essencial, cognição, ansiedade, depressão, destreza manual.

Essential tremor (ET) was long believed to be a monosymptomatic disorder where tremor is the single clinical manifestation ${ }^{1}$. However, new evidence has been produced in recent years, and it is now considered as a complex, heterogeneous disease characterized by a progressive course, that is possibly caused by different pathogenic mechanisms, with potential cognitive impairments ${ }^{2}$ suggesting non-motor compromise.
Several studies have shown that ET is associated with cognitive impairments. Lombardi et al. showed naming, short-term memory, working memory and verbal fluency deficits in 18 patients with $\mathrm{ET}^{3}$. Gasparini et al. evaluated frontal lobe dysfunction in 27 patients with ET, 15 patients with Parkinson's disease (PD) and 15 healthy controls and they found attention and verbal fluency deficits in the two former

\footnotetext{
${ }^{1}$ Universidade Federal de São Paulo, Departamento de Neurologia e Neurocirurgia, Unidade de Distúrbios do Movimento, Sao Paulo SP, Brazil; ${ }^{2}$ Hospital Israelita Albert Einstein, Instituto Israelita de Ensino e Pesquisa, Sao Paulo SP, Brazil.

Correspondence: Leonardo Mariano Inácio Medeiros; Avenida Nossa Senhora de Fátima, 60 / quadra 16;17017-337 Bauru SP, Brasil;

E-mail:doutor_medeiros@yahoo.com.br

Conflict of interest: There is no conflict of interest to declare.

Received 29 April 2015; Received in final form 04 September 2015; Accepted 24 September 2015.
} 
groups of patients compared to controls. Louis et al. recently demonstrated greater cognitive decline in patients with ET suggesting it is a potential risk factor for dementia ${ }^{4,5}$.

However, these studies ${ }^{3,4,5,6}$ have methodological limitations, including small sample size with limited age range ${ }^{4,7}$, no comparison to a control group ${ }^{3,8}$, no control for comorbidities $^{9}$, use of drugs that may affect cognition ${ }^{5}$, and other psychiatric disorders ${ }^{6}$.

Thus, in the light of the methodological limitations of previous studies and lack of studies assessing cognition in patients with ET in Brazil, we conducted a cross-sectional study to evaluate the neuropsychological performance and a screening for psychiatric symptoms in ET patients compared to two control groups of (related and unrelated) healthy individuals.

\section{METHOD}

\section{Patient selection}

We conducted the present study from November 2011 to June 2013. We selected medical records of patients previously diagnosed with ET and followed up at our clinic (having attended two or more visits). All patients were examined by at least two neurologists specialized in movement disorders and their clinical diagnoses fulfilled the consensus criteria for the diagnosis of $\mathrm{ET}^{10}$. Exclusion criteria included use of medications known to affect cognitive performance (benzodiazepines, antidepressants, anticonvulsants, antihistamines, neuroleptics and hypnotics); prior diagnosis of mood or anxiety disorders; refusal to answer the questionnaire; and less than four years of schooling. All patients selected were able to answer the study questionnaire.

\section{Clinical protocol}

The initial strategy was to select cases matched by controls at 3:1:1 ratio of three cases to one related and one unrelated control. First, we selected cases through random review of medical records and assessed them all. The patients were recruited by personal or phone invitation. Then we recruited controls who underwent a clinical examination for ruling out any type of tremor or comorbidities that could prevent their participation in the study. Related controls had to be first-degree relatives and they were recruited in order to try to detect pre motor symptoms.

A priori selection of cases included 100 medical records before applying exclusion criteria.

We collected demographic information on the following variables: gender, age, comorbidities, level of education, marital status, use of medications and disease duration.

\section{Demographic and clinical features}

Of 100 randomly selected medical records, 44 patients with ET were included in the final sample. We excluded 56 patients for different reasons (40\% attended only one visit; $30 \%$ had less than four years of schooling; $20 \%$ were diagnosed with mood disorders; and $10 \%$ were on psychotropic medication). After the inclusion of patients in the study, we actively recruited related and unrelated controls. We divided them into three groups: ET $(n=44)$; first-degree relatives without tremor $(\mathrm{n}=20)$; and unrelated individuals without tremor $(n=39)$. We reached a ratio of approximately 2:1:2.

Demographic characteristics of the sample studied are presented in Table 1. There was a significantly greater proportion of females among unrelated controls and of younger individuals among related controls.

Regarding comorbidities, there was no difference between patients with ET and related $(\mathrm{p}=0.083)$ and unrelated controls $(p=0.110)$. Related controls had lower prevalence of heart diseases compared to unrelated controls $(p=0.005)$.

Tremor was assessed using the Fahn-Tolosa-Marin Tremor Rating Scale (TRS $)^{11}$, translated into Portuguese and validated for the Brazilian population ${ }^{12}$. We calculated the total TRS

Table 1. Distribution of cases and controls according to sociodemographic characteristics.

\begin{tabular}{|c|c|c|c|c|}
\hline \multirow{2}{*}{ Variables } & ET & Unrelated controls & Related controls & \multirow{2}{*}{$\mathrm{p}$-value } \\
\hline & $N(\%)$ & $N(\%)$ & $\mathrm{N}(\%)$ & \\
\hline Gender & & & & 0.046 \\
\hline Male & $19(43.2)$ & $7(18.0)$ & $6(30.0)$ & \\
\hline Female & $2(56.8) *$ & $32(82.0) *$ & $14(70.0)$ & \\
\hline Age (years) & & & & $<0.001$ \\
\hline$\leq 50$ & $13(29.5) * *$ & $5(12.8) * \star$ & $13(65.0)^{\star \star}$ & \\
\hline$>50$ & $31(70.5)$ & $34(87.2)$ & $7(35.0)$ & \\
\hline Schooling (years) & & & & 0.159 \\
\hline $4-8$ & $13(29.5)$ & $10(25.6)$ & $2(10.0)$ & \\
\hline $9-11$ & $15(34.1)$ & $12(30.8)$ & $4(20.0)$ & \\
\hline 12 or more & $16(36.4)$ & $17(43.6)$ & $14(70.0)$ & \\
\hline Marital status & & & & 0.933 \\
\hline Married & $22(50.0)$ & $20(51.3)$ & $11(55.0)$ & \\
\hline Single/divorced/widowed & $22(50.0)$ & $19(48.7)$ & $9(45.0)$ & \\
\hline Total & $44(100)$ & $39(100)$ & $20(100)$ & \\
\hline
\end{tabular}

${ }^{\star}$ Comparative difference between the groups in relation to gender; ${ }^{\star \star}$ Comparative difference between the groups in relation to age. 
score as follows: (Part A + Part B + Part C) / 156 x 100. The higher the final score (\%) the more severe the patient's condition.

All patients were assessed using the Montreal Cognitive Assessment (MoCA) ${ }^{13}$, validated for Brazilian population ${ }^{14}$, for global cognitive evaluation. In addition, the following neuropsychological assessment battery was used: Pegboard test (manual dexterity, bimanual coordination and attention) ${ }^{15}$; Forward and Backward digit-span task (attention and immediate memory) ${ }^{16}$; Semantic Verbal fluency (semantic categories of animals and fruits) (executive function) ${ }^{17,18}$; Brown-Peterson task (short-term memory and attention) $)^{19,20}$; and the Frontal Assessment Battery (FAB) (Part 1) (abstraction and similarity) ${ }^{21}$.

We first compared cognitive test results among the three groups. Then we compared patients with ET older than 65 with unrelated controls following the same methodological approach of prior studies ${ }^{3,4,6,22}$. We also used the cut-off of age 65 to compare cognitive test results among patients with ET to check for any age-related changes.

We compared demographic characteristics and presence of depression and anxiety symptoms in all analyses. Comorbidities studied were heart, kidney, endocrine, infectious and musculoskeletal conditions.

We also carried out a separate analysis including patients receiving or not primidone for the treatment of ET. Primidone is metabolized to phenobarbital that can cause somnolence and cognitive impairment as side effects ${ }^{23,24}$ and could affect the results.

The Hospital Anxiety and Depression Scale (HADS) was used to screen for depression and anxiety disorders. A score of nine was set as cut-off for each subsection, HADS-Anxiety (HADS-A) and HADS-Depression (HADS-D), as suggested by Zigmond and Snaith ${ }^{25}$.

This study was approved by the local Research Ethics Committee (CEP/UNIFESP 5609/12). All participants signed an informed consent form.

\section{Statistical analysis}

The Shapiro-Wilk test was used to test for the normality of the data and the independent two-tailed Student's t-test to assess parametric data. Mann-Whitney test was performed to compare nonparametric data, the chi-square test to compare frequencies, and Fisher's exact test to analyze contingency data. We conducted ANOVA with Bonferroni's post hoc test for multiple comparisons or the Kruskal-Wallis test after non-normality of the data was verified in the ShapiroWilk test. Data were presented as mean $(\mathrm{m}) \pm$ standard deviation (SD) or as number of subjects (n) and percentage (\%). The statistical significance was set at $\mathrm{p} \leq 0.05$.

\section{RESULTS}

\section{Analysis of cognitive aspects}

The groups studied showed no statistically significant differences in results of the MoCA test $(p=0.653)$, Forward digit-span task ( $\mathrm{p}=0.056)$, Backward digit-span task ( $p=0.074)$, Verbal fluency (semantic category of fruits) $(p=0.117)$ and Similarity test $(p=0.728)$ (Table 2$)$.

A significant difference in mean scores of the three groups was found on the Brown-Peterson test $(p=0.029)$, Verbal fluency (semantic category of animals) $(p=0.041$ ) and Pegboard test (right hand, left hand and both hands, $\mathrm{p}<0.001$ ). A significant difference in mean scores of the Brown-Peterson test was seen between patients with ET and related controls $(\mathrm{p}=0.024)$. On the Pegboard test, patients with ET had lower scores compared to related and unrelated controls in all tasks. The findings are as follow: right hand test ( $p<0.001$ for patients versus unrelated controls and patients versus related controls; left hand test $(\mathrm{p}=0.009$ for $\mathrm{pa}-$ tients versus unrelated controls and $\mathrm{p}=0.001$ for patients versus related controls); and both hands working together

Table 2. Results of the cognitive tests obtained for patients with essential tremor (ET) versus related and unrelated controls (mean (SD)).

\begin{tabular}{|c|c|c|c|c|}
\hline \multirow{2}{*}{$\mathrm{N}$} & ET & Unrelated controls & Related controls & \multirow{2}{*}{$p$-value } \\
\hline & 44 & 39 & 20 & \\
\hline \multicolumn{5}{|l|}{ Cognitive tests } \\
\hline MoCA & $25.8(2.9)$ & $25.8(2.5)$ & $25.6(4.3)$ & $0.653 * * *$ \\
\hline Forward digit-span task & $5.3(1.5)$ & $4.9(1.1)$ & $5.7(1.2)$ & $0.056 * \star \star$ \\
\hline Backward digit-span task & $4.0(1.2)$ & $4.0(1.0)$ & $4.7(1.2)$ & 0.074 \\
\hline Brown-Peterson task & $6.3(3.6)$ & $7.3(3.6)$ & $9.0(4.4) \star$ & 0.029 \\
\hline Pegboard test with right hand & $10.9(3.2)$ & $13.5(1.6)^{\star}$ & $14.4(2.7)^{\star}$ & $<0.001 * * * *$ \\
\hline Pegboard test with left hand & $10.1(2.8)$ & $11.9(2.8)^{*}$ & $12.9(2.0)^{\star}$ & $<0.001$ \\
\hline Pegboard test with both hands & $17.2(5.1)$ & $20.6(4.0)^{\star}$ & $22.8(5.6)^{\star}$ & $<0.001 * \star \star$ \\
\hline Verbal fluency (animals) & $18.2(4.6)$ & $18.1(6.2)$ & $21.2(7.6)^{\star}$ & $0.041 * \star \star$ \\
\hline Verbal fluency (fruits) & $15.0(3.8)$ & $15.3(3.9)$ & $17.2(4.4)$ & 0.117 \\
\hline \multicolumn{5}{|l|}{ Similarity test } \\
\hline 0 or 1 & $2(4.5 \%)$ & $1(2.6 \%)$ & $1(5.0 \%)$ & $0.728 * \star$ \\
\hline 2 & $13(29.6 \%)$ & $17(43.6 \%)$ & $8(40.0 \%)$ & \\
\hline 3 & $29(65.9 \%)$ & $21(53.8 \%)$ & $11(55.0 \%)$ & \\
\hline
\end{tabular}


$(p=0.007$ for patients versus unrelated controls and $p<0.001$ for patients versus related controls).

In the semantic category of animals of the Verbal fluency test, both patients with ET and unrelated controls showed lower scores than related controls $(\mathrm{p}=0.030$ and $\mathrm{p}=0.015$, respectively). This difference could be explained by lower age of the related controls.

A comparison of patients with unrelated controls older than 65 showed no significant differences with regard to gen$\operatorname{der}(p=0.162)$, level of education $(p=0.803)$ and marital status ( $p=0.492)$. In addition, there was no difference regarding comorbidities and results of the following cognitive tests: MoCA $(p=0.789)$, Forward digit-span task ( $p=0.356)$, Backward digitspan task ( $p=0.525)$, Brown-Peterson test $(p=0.188)$, Verbal fluency (category of animals) $(p=0.073)$, Verbal fluency (category of fruits) $(p=0.892)$ and Similarity test $(p=0.262)$. However, patients with ET were older than controls $(p=0.049)$ and had lower mean scores on the Pegboard test with right hand ( $p<0.001)$, left hand $(p=0.015)$ and both hands $(p=0.002)$. We made no comparisons between patients and related controls as the maximum age in this group was 64 years.

A comparison between younger and older than 65 ET patients showed higher mean scores on the Forward digit-span test $(p=0.033)$, Brown-Peterson test $(p=0.020)$, Pegboard test with right hand $(p=0.003)$, left hand $(p<0.001)$ and both hands $(p=0.001)$ among those aged up to 65 .

We found no significant correlation between cognitive test results and disease duration (Table 3). However, we found a negative significant correlation between disease severity and some cognitive test results (Table 3).

Table 4 shows cognitive test results according to the presence of depression and anxiety symptoms.

Finally, we found that patients with ET on primidone had lower mean scores on the MoCA ( $p=0.021)$, Pegboard with right hand ( $p=0.002)$, left hand $(\mathrm{p}<0.001)$ and both hands $(\mathrm{p}=0.002)$ when compared to patients without use of primidone.

\section{DISCUSSION}

The results of this study suggest that patients with ET are more likely to have manual dexterity and attention deficits, with no differences compared to the control groups in cognitive or other psychiatric functions assessed. In addition, patients with more severe disease showed poorer performance on cognitive tests. Another important finding of this study

Table 3. Correlation coefficients between cognitive test results and duration or severity of essential tremor.

\begin{tabular}{|c|c|c|c|c|}
\hline \multirow{2}{*}{ Cognitive tests } & \multicolumn{2}{|c|}{ Disease duration } & \multicolumn{2}{|c|}{ Disease severity* } \\
\hline & $r_{s}$ & $\mathrm{p}$-value & $r_{s}$ & $p$-value** \\
\hline Moca & 0.030 & 0.847 & -0.346 & 0.022 \\
\hline Forward digit-span task & -0.114 & 0.460 & -0.341 & 0.024 \\
\hline Backward digit-span task & -0.245 & 0.110 & -0.357 & 0.017 \\
\hline Brown-peterson task & -0.079 & 0.613 & -0.421 & 0.005 \\
\hline Pegboard test with right hand & 0.002 & 0.989 & -0.419 & 0.005 \\
\hline Pegboard test with left hand & -0.099 & 0.522 & -0.461 & 0.002 \\
\hline Pegboard test with both hands & -0.054 & 0.728 & -0.502 & $<0.001$ \\
\hline Verbal fluency (animals) & -0.020 & 0.899 & -0.268 & 0.079 \\
\hline Verbal fluency (fruits) & 0.052 & 0.738 & -0.436 & 0.003 \\
\hline Similarity test & 0.072 & 0.644 & 0.086 & 0.580 \\
\hline
\end{tabular}

rS: Spearman's correlation test; MoCA: Montreal Cognitive Assessment; *Disease severity according the total score of the Fahn-Tolosa-Marin Tremor Rating Scale; $* * p<0.05$.

Table 4. Analysis of cognitive test results according to the presence or not of psychiatric comorbidity (mean \pm standard deviation).

\begin{tabular}{|c|c|c|c|c|c|c|}
\hline \multirow{2}{*}{ Cognitive tests } & \multicolumn{3}{|c|}{ Anxiety } & \multicolumn{3}{|c|}{ Depression } \\
\hline & No $(n=29)$ & Yes $(n=15)$ & $p$-value* & No $(n=35)$ & Yes $(n=9)$ & $p$-value* \\
\hline MoCA & $25.7(2.9)$ & $25.9(3.0)$ & 0.413 & $26.2(2.8)$ & $24.1(2.8)$ & $0.003 * \star$ \\
\hline Forward digit-span task & $5.5(1.5)$ & $4.7(1.4)$ & $0.055^{\star *}$ & $5.5(1.5)$ & $4.3(1.1)$ & 0.003 \\
\hline Backward digit-span task & $4.1(1,4)$ & $3.8(0.9)$ & $0.047 * \star$ & $4.1(1.3)$ & $3.8(1.1)$ & 0.179 \\
\hline Brown-Peterson task & $6.2(3.7)$ & $6.4(3.7)$ & 0.929 & $6.7(3.3)$ & $4.4(2.9)$ & 0.035 \\
\hline Pegboard test with right hand & $10.1(3.1)$ & $12.4(2.8)$ & 0.048 & $10.6(3.1)$ & $12.1(3.3)$ & 0.774 \\
\hline Pegboard test with left hand & $9.4(2.7)$ & $11.4(2.6)$ & 0.168 & $9.8(2.8)$ & $11.1(2.8)$ & 0.750 \\
\hline Pegboard test with both hands & $16.0(5.0)$ & $19.6(4.7)$ & 0.132 & $17.0(5.1)$ & $18.2(5.2)$ & 0.495 \\
\hline Verbal fluency (animals) & $18.0(4.3)$ & $18.5(4.3)$ & 0.594 & $18.4(4.7)$ & $17.2(3.9)$ & 0.010 \\
\hline Verbal fluency (fruits) & $14.8(3.9)$ & $15.3(3.8)$ & 0.997 & $15.5(3.7)$ & $13.2(3.8)$ & 0.012 \\
\hline Disease duration & $20.0(18.2)$ & $26.2(11.6)$ & $0.037 \star \star$ & $21.8(17.6)$ & $23.4(11.3)$ & $0.388 * \star$ \\
\hline Disease intensity & $16.0(8.7)$ & $17.0(7.1)$ & $0.347 * \star$ & $15.6(8.0)$ & $19.8(8.5)$ & $0.167 * \star$ \\
\hline
\end{tabular}


was that patients with ET with depression and/or anxiety symptoms and those on use of primidone showed poorer manual dexterity and cognitive performance.

We decided to keep a control group of patients' relatives trying to find pre motor subclinical change. This could support the hypothesis of a disease with greater range of symptoms but that was not the finding in our study.

A comparison between groups showed significant age and gender differences. This could be explained by the fact that unrelated controls were recruited through educational lectures attended by a greater proportion of females, which is in agreement to that described in the literature ${ }^{26}$. As for age, healthy controls had to attend a visit at the study site for testing, which made it difficult for older ones. In addition, many relatives of patients lived far from the study site and those who lived closer were their children. We found no statistical differences between ET patients and controls in results on the MoCA test, Verbal fluency (categories of animals and fruits) and Similarity test, but we found a difference in the Forward and Backward digit-span task. These results contrast with those reported in other studies ${ }^{3,6,79}$. One of the most important points of our study was to demonstrate that there was no difference in neuropsychological assessment in patients with ET compared with controls when controlled properly some biases.

The authors of the NEDICES study reported that patients with ET showed poorer verbal fluency in the semantic category of fruits'; nevertheless, mean age of their patients was higher than that of the patients in our study (75 vs. 60 years, respectively). Even after comparing only those over 65 , we found no significant differences in verbal fluency. Furthermore, when we checked the cutoff point in the Verbal fluency test, semantic category of animals, for the Brazilian population ${ }^{27}$, we found that the mean score on the test was higher than the proposed one, demonstrating no loss of the cognitive function assessed. We saw significant differences only in test results of the Pegboard test and Brown-Peterson task.

We found manual dexterity and coordination deficits among patients with ET compared to controls in the Pegboard test. To our best knowledge, there is no study in the literature with patients with ET using the Pegboard test to assess manual dexterity. We may assume these findings could be related not only to dexterity but also to attention deficits. Some studies assessing patients with ET showed they had poorer quality of life than healthy controls. The most affected domains were functional performance and physical limitation ${ }^{28,29}$, which may be explained by impaired manual dexterity.

With regard to the Brown-Peterson task, patients with ET showed lower scores that were significantly different only when compared to scores in related controls. Related controls had lower mean age, which may suggest that age may affect attention and working memory, as assessed in this test. This was verified when we compared patients and unrelated controls age 65 years or more: we found no significant difference in the Brown-Peterson task scores. Yet, this difference was evidenced once again when we compared patients with ET younger and older than 65. In a 2001 study, Gasparini et al. found executive function and attention deficits in patients with ET compared to controls suggestive of frontal lobe dysfunction ${ }^{6}$. The NEDICES study also showed abnormal results in attention assessment tests?.

Kim et al. compared 34 patients with ET with 33 controls and found significant difference mainly in the Forward and Backward digit-span task and Verbal fluency test, but they did not assess depression and anxiety disorders, and use of medications that could affect cognitive performance ${ }^{22}$. Our study found a difference when we compared patients with ET younger and older than 65 , indicating an overall deficit of attention with age.

Many studies evaluating cognitive aspects in patients with ET did not investigate the effects of depression and anxiety disorders and psychotropic medication use. In our study, we excluded patients on medications that may affect cognitive ability and those previously diagnosed with depression and anxiety disorders. Yet, we screened for depression and anxiety symptoms. A comparison between anxiety and non-anxiety patients showed altered results mainly in the Backward digit-span task that requires a high level of attention and in the Pegboard test with the right hand. Another interesting finding was a higher prevalence of anxiety found among patients with longer disease duration.

With regard to depression, we found lower scores on the MoCA test, Forward digit-span task, Brown-Peterson task and Verbal Fluency, in both categories of animals and fruits. Contrasting with Duane et al. findings, we found a lower frequency of depression and anxiety symptoms in our study $(20.5 \% \text { vs. } 55 \% \text { of depression, and } 34.1 \% \text { vs. } 49 \% \text { of anxiety })^{30}$.

As for the use of medications that may affect cognitive ability, we included in the study only patients on use of primidone. A comparison of patients who were on primidone and those who were off primidone showed differences in the Pegboard test and the MoCA. Possibly this can be explained by a greater mean age of patients on primidone and its metabolic effects ${ }^{24}$.

We did not find a correlation of cognitive test results with disease duration but we did find it with disease severity. Lombardi et al. and Troster et al. evaluated patients unresponsive to medication requiring surgical treatment $t^{3,7}$, and they were found to have more severe disease, which could explain the abnormal results in cognitive assessment.

A number of important limitations of this study need to be considered. A major limitation was the use of a cross-sectional design as we were unable to assess time of onset and progression of cognitive symptoms in parallel to other features of ET. Our study was also limited by a greater proportion of females in the control group compared with cases. We also did not assess the correlation of ET with other areas of cognition (for example, visuo-spatial function). 
Notwithstanding the aforementioned limitations, our study was able to show that patients with ET had manual dexterity and attention deficits with no impairments in other cognitive functions studied. In addition, patients with more severe disease showed poorer performance on cognitive tests. Cognitive symptoms and poor manual dexterity were more common among those with depression and anxiety symptoms as well as those taking primidone.

\section{References}

1. Grau-Veciana JM, Peiro Grasa A. [Benign essential tremor. Review of a series of cases]. Neurologia. 1986;1(5):198-201. Spanish.

2. Jankovic J. Essential tremor: a heterogenous disorder. Mov Disord. 2002;17(4):638-44. doi:10.1002/mds.10221

3. Lombardi WJ, Woolston DJ, Roberts JW, Gross RE. Cognitive deficits in patients with essential tremor. Neurology. 2001;57(5):785-90. doi:10.1212/WNL.57.5.785

4. Louis ED, Viner AS, Gillman A. Mental status test scores are inversely correlated with tremor severity: a study of 161 elderly essential tremor cases. Tremor Other Hyperkinet Mov (N Y). 2012;2:tre-02-69-279-1.

5. Benito-Leon J, Louis ED, Sanchez-Ferro A, Bermejo-Pareja F. Rate of cognitive decline during the premotor phase of essential tremor: a prospective study. Neurology. 2013;81(1):60-6. doi:10.1212/WNL.0b013e318297ef2b

6. Gasparini M, Bonifati V, Fabrizio E, Fabbrini G, Brusa L, Lenzi GL et al. Frontal lobe dysfunction in essential tremor: a preliminary study.J Neurol. 2001;248(5):399-402. doi:10.1007/s004150170181

7. Woods SP, Scott JC, Fields JA, Poquette A, Troster Al. Executive dysfunction and neuropsychiatric symptoms predict lower health status in essential tremor. Cogn Behav Neurol. 2008;21(1):28-33. doi:10.1097/WNN.0b013e3181684414

8. Lacritz LH, Dewey R Jr, Giller C, Cullum CM. Cognitive functioning in individuals with "benign" essential tremor. J Int Neuropsychol Soc. 2002;8(1):125-9. doi:10.1017/S1355617702001121

9. Benito-Leon J, Louis ED, Bermejo-Pareja F. Population-based case-control study of cognitive function in essential tremor. Neurology. 2006;66(1):69-74. doi:10.1212/01.wnl.0000192393.05850.ec

10. Deuschl G, Bain P, Brin M. Consensus statement of the Movement Disorder Society on Tremor. Mov Disord. 1998;13(S3):2-23. doi:10.1002/mds.870131303

11. Fahn S, Tolosa E, Marin C. Clinical rating scale for tremor. In: Jankovic J, Tolosa E, editors. Parkinson's disease and movement disorders. 3rd ed. Michigan: Michigan University Press 1993. p. 271-80. Williams \& Wilkins.

12. Nicaretta DH, Pereira JS, Pimentel MLV. Tremor: adaptação de uma escala clínica. Arq Neuropsiquiatr. 1997;55(3a):381-6. doi:10.1590/S0004-282X1997000300005

13. Price CC, Cunningham $\mathrm{H}$, Coronado N, Freedland A, Cosentino S, Penney DL et al. Clock drawing in the Montreal Cognitive Assessment: recommendations for dementia assessment. Dement Geriatr Cogn Disord. 2011;31(3):179-87. doi:10.1159/000324639

14. Bertolucci PHF, Sarmento ALR, Wajman JR. P4-062: Brazilian Portuguese version for the Montreal Cognitive Assessment (MoCA) and the preliminary results. Alzheimers Dement (NY). 2008;4(4 suppl):T686. doi:10.1016/j.jalz.2008.05.2127

15. Tiffin J, Asher EJ. The Purdue pegboard; norms and studies of reliability and validity. J Appl Psychol. 1948;32(3):234-47. doi:10.1037/h0061266
16. Wechsler D. WMS-R: Wechsler memory scale-revised: manual. 3rd ed. Harcourt Brace Jovanovich; 1987.

17. Strauss E, Sherman EMS, Spreen O. A compendium of neuropsychological tests: administration, norms, and commentary. 3rd ed. Oxford: Oxford University Press; 2006.

18. Brucki SM, Rocha MS. Category fluency test: effects of age, gender and education on total scores, clustering and switching in Brazilian Portuguese-speaking subjects. Braz J Med Biol Res. 2004;37(12):1771-7. doi:10.1590/S0100-879X2004001200002

19. Anil AE, Kivircik BB, Batur S, Kabakçi E, Kitis A, Güven E, et al. The Turkish version of the auditory consonant trigram test as a measure of working memory: a normative study. Clin Neuropsychol. 2003;17(2):159-69. doi:10.1076/clin.17.2.159.16510

20. Mertens VB, Gagnon M, Coulombe D, Messier C. Exploratory factor analysis of neuropsychological tests and their relationship to the Brown-Peterson task. Arch Clin Neuropsychol. 2006;21(7):733-9. doi:10.1016/j.acn.2006.08.005

21. Beato RG, Nitrini R, Formigoni AP, Caramelli P. Brazilian version of the Frontal Assessment Battery (FAB): preliminary data on administration to healthy elderly. Dement Neuropsychol. 2007;1(1):59-65.

22. Kim JS, Song IU, Shim YS, Park JW, Yoo JY, Kim YI et al. Cognitive Impairment in Essential Tremor without Dementia. J Clin Neurol. 2009;5(2):81-4. doi:10.3988/jcn.2009.5.2.81

23. Ding D, Zhang Q, Zhou D, Lin W, Wu Q, Sun J et al. Cognitive and mood effects of phenobarbital treatment in people with epilepsy in rural China: a prospective study. J Neurol Neurosurg Psychiatry. 2012;83(12):1139-44. doi:10.1136/jnnp-2012-303042

24. Brodie MJ, Kwan P. Current position of phenobarbital in epilepsy and its future. Epilepsia. 2012;53(Suppl s8):40-6. doi:10.1111/epi.12027

25. Zigmond AS, Snaith RP. The hospital anxiety and depression scale. Acta psychiatrica Scandinavica. 1983;67(6):361-70. doi:10.1111/j.1600-0447.1983.tb09716.x

26. Ministério da Saúde (BR), Secretaria de Vigilância em Saúde. Saúde Brasil 2007: uma análise da situação de saúde. Brasília, DF: Ministério da Saúde; 2008. (Série G Estatística e informação em saúde).

27. Brucki SMD, Malheiros SMF, Okamoto IH, Bertolucci PHF. Dados normativos para o teste de fluência verbal categoria animais em nosso meio. Arq Neuropsiquiatr. 1997;55(1):56-61. doi:10.1590/S0004-282X1997000100009

28. Benito-León J, Louis ED. Clinical update: diagnosis and treatment of essential tremor. Lancet. 2007;369(9568):1152-4. doi:10.1016/S0140-6736(07)60544-3

29. Lorenz D, Schwieger D, Moises H, Deuschl G. Quality of life and personality in essential tremor patients. Mov Disord. 2006;21(8):1114-8. doi:10.1002/mds.20884

30. Duane DD, Vermilion KJ. Cognitive deficits in patients with essential tremor [author rely]. Neurology. 2002;58(11):1706-7. doi:10.1212/WNL.58.11.1706 